\title{
Involvement of Actin Microfilament in Regulation of Pacemaking Activity Increased by Hypotonic Stress in Cultured ICCs of Murine Intestine
}

\author{
Z. Y. WANG ${ }^{1}$, X. HUANG ${ }^{1}$, D. H. LIU ${ }^{1}$, H. L. LU ${ }^{1}$, Y. C. KIM ${ }^{2}$, W. X. XU ${ }^{1}$ \\ ${ }^{1}$ Department of Physiology, Shanghai Jiaotong University School of Medicine Shanghai, China, \\ ${ }^{2}$ Department of Physiology, Chungbuk National University College of Medicine, Hungduk-gu, \\ Cheongju, Chungbuk, Korea
}

Received July 19, 2014

Accepted October 24, 2014

On-line December 22, 2014

\section{Summary}

Distension is a regular mechanical stimulus in gastrointestinal (GI) tract. This study was designed to investigate the effect of hypotonic stress on pacemaking activity and determine whether actin microfilament is involved in its mechanism in cultured murine intestinal interstitial cells of Cajal (ICCs) by using whole-cell patch-clamp and calcium imaging techniques. Hypotonic stress induced sustained inward holding current from the baseline to $-650 \pm 110 \mathrm{pA}$ and significantly decreased amplitudes of pacemaker current. Hypotonic stress increased the intensity of basal fluorescence ratio (F/FO) from baseline to $1.09 \pm 0.03$ and significantly increased $\mathrm{Ca}^{2+}$ oscillation amplitude. Cytochalasin-B $(20 \mu \mathrm{M})$, a disruptor of actin microfilaments, significantly suppressed the amplitudes of pacemaker currents and calcium oscillations, respectively. Cytochalasin-B also blocked hypotonic stress-induced sustained inward holding current and hypotonic stress-induced increase of calcium oscillations. Phalloidin $(20 \mu \mathrm{M})$, a stabilizer of actin microfilaments, significantly enhanced the amplitudes of pacemaker currents and calcium oscillations, respectively. Despite the presence of phalloidin, hypotonic stress was still able to induce an inward holding current and increased the basal fluorescence intensity. These results suggest that hypotonic stress induces sustained inward holding current via actin microfilaments and the process is mediated by alteration of intracellular basal calcium concentration and calcium oscillation in cultured intestinal ICCs.

\section{Key words \\ ICCs - Hypotonic stress • Actin microfilament • Pacemaking activity $\bullet$ Calcium oscillation \\ Corresponding author \\ W. X. Xu, Department of Physiology, Shanghai Jiaotong University School of Medicine, 800 Dongchuan Rd, 328 Wenxuan Medical Building, Shanghai 200240, China. E-mail: wenxiexu@sjtu.edu.cn}

\section{Introduction}

The intrinsic (i.e. non-neural, non-hormonal) regulation of gut motility has been referred to in the literature as "myogenic", but it is now recognized that the traditional use of this term includes, besides smooth muscle mechanisms, the behavior of intestinal interstitial cells of Cajal (ICCs) (Sanders 2008). ICCs are electrically coupled to smooth muscle cell, and affect resting membrane potentials of the smooth muscle/ICCs syncytium and impose pacemaking activity, sensitivity to stretch and responsiveness to neurotransmitters (Sanders et al. 2006) on the behavior of smooth muscle cell. Mechanosensitivity underlies several of the fundamental processes that are required for effective gastrointestinal (GI) function. The GI tract is required to "sense" force and translate it to a chemical or electrical signal (Kraichely and Farrugia 2007).

ICCs are responsible for spontaneous and 
rhythmic electrical activity in GI tract. Although the mechanosensitivity underlying several fundamental processes of GI smooth muscle has been studied considerably, little is known about the mechanosensitivity underlying the pacemaking activity of ICCs. Stretch-dependent responses in antrum were mediated by ICCs-IM because no response was observed in antral muscles of $\mathrm{W} / \mathrm{W}^{\mathrm{V}}$ mice which lack ICCs-IM (Burns et al. 1996). The transient receptor potential (TRP) superfamily of non-selective channels has been identified in GI smooth muscle and ICCs (Kim et al. 2006). The TRP channels, in general, have multiple gating mechanisms. Several TRP channels including TRPA1 (Corey et al. 2004) and TRPC1 (Maroto et al. 2005) have been demonstrated to have mechanosensitivity. Strege et al. (2003) observed a mechanosensitive sodium channel current in human intestinal ICCs. They suggested that the channel may play an important role in normal physiological control of human intestinal motor function by contributing to setting of membrane potential, the rate of rise of slow wave and mechanosensitive regulation of slow wave frequency. A previous study at the tissue level also demonstrated that increasing muscle length resulted in significant changes in the resting potentials and intrinsic frequency of antral pacemakers (Won et al. 2005). Recently, ICCs have also been suggested to act as a stretch receptor to detect circumferential expansion and swelling of GI tract wall and trigger the contraction of smooth muscle (Aranishi et al. 2009).

The actomyosin cytoskeleton is a large network of structural, motor and signaling proteins that coordinate a plethora of cellular functions including cell division, adhesion and migration. Actin microfilaments were necessary in regulation of cell response to physical forces (Higashida et al. 2013). The activities of various transport proteins as well as ion and water permeable channels have been shown to be dependent on the extent of actin polymerization (Prat et al. 1993, Constantin 2013). Our previous study also demonstrated that actin microfilament is involved in regulation of pacemaker currents in cultured intestinal ICCs (Wang et al. 2010a). However, little is known about the direct effect of hypotonic stress on ICCs pacemaker current. Accordingly, the present study was aimed to clarify the effect of hypotonic stress on ICCs pacemaker current and to test whether actin cytoskeleton takes part in this mechanism in cultured murine intestinal ICCs by using patch clamp and $\mathrm{Ca}^{2+}$ fluorescence techniques.

\section{Materials and Methods}

\section{Preparation of cells}

Balb/C mice (7-13 days old) of either sex were obtained from the Experimental Animal Center of the Chinese Academy of Science. Animals were killed by cervical dislocation. The small intestine was dissected from $1 \mathrm{~cm}$ below the pyloric ring to the cecum, and luminal contents were washed out with Krebs-Ringer bicarbonate (KRB). Tissues were pinned to the base of a Sylgard dish and the mucosae removed. Small strips of intestinal muscle were incubated at $37^{\circ} \mathrm{C}$ for $23 \mathrm{~min}$ in enzyme solution comprising: $1.3 \mathrm{mg} / \mathrm{ml}$ collagenase (type II, Worthington), $2 \mathrm{mg} / \mathrm{ml}$ bovine serum albumin (Sino-American Biotechnology Co., China), $2 \mathrm{mg} / \mathrm{ml}$ trypsin inhibitor (Amresco, OH, USA) and $0.27 \mathrm{mg} / \mathrm{ml}$ ATP (Sigma Aldrich, St. Louis, MO, USA). The muscle strips were then washed three times to remove the enzyme before being triturated through blunt pipettes. The resulting cell suspension was plated on murine collagen-coated $(2.5 \mu \mathrm{g} / \mathrm{ml})$ sterile glass cover slips in culture dishes. Cells were allowed to settle for $30 \mathrm{~min}$ before adding SMGM medium (Clonetics Corp, San Diego, CA, USA) supplemented with $2 \%$ antibiotics/ antimycotics (Gibco Invitrogen Corp, Grand Island, USA) and murine stem cell factor (SCF, $5 \mathrm{ng} / \mathrm{ml}$, Sigma Aldrich, St. Louis, MO, USA). Cells were then incubated at $37^{\circ} \mathrm{C}$ in a $5 \% \mathrm{CO}_{2}$ incubator. The above methods were performed as described in Zhang et al. (2006) and the cultured cells have been confirmed to be ICCs.

All experimental protocols were approved by the local animal care committee and conformed with the Guide for the Care and Use of Laboratory Animals published by the Science and Technology Commission of P.R.C (STCC Publication No.2, revised 1988).

\section{$\mathrm{Ca}^{2+}$ fluorescent imaging}

Cultured ICCs $(48-72 \mathrm{~h})$ were loaded with the $\mathrm{Ca}^{2+}$-sensitive indicator Fluo-3AM $(8 \mu \mathrm{M})$ and Pluronic $\mathrm{F}-127(0.03 \%)$ for $2 \mathrm{~h}$ at $37^{\circ} \mathrm{C}$ and washed for a further $30 \mathrm{~min}$ in physiological salt solution (PSS) for de-esterification. A microscope (Olympus BX51, Japan) equipped with a Hamamatsu 1394 Orca-ER CCD camera (Hamamatsu, Japan) was used to monitor and record digital images. Simple PCI 6 software (Compix Inc., USA) was used for data analysis. Cells were illuminated at $488 \mathrm{~nm}$ and emission light of $515-565 \mathrm{~nm}$ was detected. Fluorescence intensity was expressed as a fluorescence ratio (F/F0), elucidating $\mathrm{Ca}^{2+}$ fluorescence 
intensity from its arbitrary resting fluorescence intensity (F0). All recordings were made at room temperature with digital images recorded every second.

\section{Patch clamp experiments}

The whole cell patch clamp technique was used to record inward currents (voltage clamp) and membrane potential (current clamp) from cultured ICCs (48-72 h). Glass pipettes with a resistance of 3-5 $\mathrm{M} \Omega$ were used to form giga seals. Electric signals were amplified with an EPC-10 patch clamp amplifier (HEKA Instrument, Germany) and digitized with a PCI-16 A/D converter (HEKA Instrument, Germany). Data were analyzed using Origin 6.0 and Sigmaplot 2.0. All recordings were made at $30^{\circ} \mathrm{C}$.

\section{Solutions and drugs}

The KRB solution comprised (mM): $\mathrm{KCl} 4.7$, $\mathrm{NaCl} 117, \mathrm{CaCl}_{2}$ 2.6, Glucose 11, $\mathrm{MgSO}_{4} 1.2, \mathrm{KH}_{2} \mathrm{PO}_{4}$ 1.2 and $\mathrm{NaHCO}_{3} 25$; and was bubbled with $95 \% \mathrm{O}_{2} / 5 \%$ $\mathrm{CO}_{2}$ (final $\mathrm{pH} 7.4$ ). PSS comprised (mM): $\mathrm{KCl} 4.5$, $\mathrm{NaCl} 135, \quad \mathrm{CaCl}_{2} 2, \quad$ Glucose $10, \quad \mathrm{MgCl}_{2}$ 1, 4-(2hydroxyethyl)-1-piperazineethanesulfonic acid (HEPES) 10 (final $\mathrm{pH}$ adjusted to 7.4 with Tris). Isotonic bath solution (310 mOsm) contained (mM): $\mathrm{KCl} 4.5, \mathrm{NaCl} 95$, $\mathrm{CaCl}_{2}$ 2, Glucose 5, $\mathrm{MgCl}_{2}$ 1, HEPES 10, sucrose 90; the $\mathrm{pH}$ was adjusted to 7.4 with Tris. Hypotonic solution ( $220 \mathrm{mOsm})$ had no sucrose but the other ingredients were the same as for the isotonic solution. The pipette solution comprised (mM): $\mathrm{KCl} 140, \mathrm{MgCl}_{2} 5, \mathrm{~K}_{2} \mathrm{ATP} 2.7$, $\mathrm{Na}_{2}$ GTP 0.1, creatine phosphate (disodium salt) 2.5, HEPES 5 and ethylene glycol tetraacetic acid (EGTA) 0.1 (final $\mathrm{pH}$ adjusted 7.2 with Tris).

Cytochalasin-B and phalloidin were dissolved in dimethyl sulfoxide (DMSO) to provide stock solutions stored at $-20{ }^{\circ} \mathrm{C}$ until use. EGTA was dissolved in distilled water. Fluo-3AM and Pluronic F-127 were purchased from AnaSpec Inc. All other drugs/agents were purchased from Sigma (Aldrich, St. Louis, MO, USA).

\section{Statistical analysis and presentation}

Data are expressed as mean \pm SEM. Differences between data sets were evaluated using paired t-tests. $\mathrm{P}<0.05$ were considered significant. The $\mathrm{n}$ values reported correspond to the number of cells were analyzed in each experiment.

\section{Results}

Effect of hypotonic stress on ICCs pacemaker current and $\left[\mathrm{Ca}^{2+}\right]_{i}$

Under whole cell voltage clamp mode the spontaneous and rhythmic inward currents were recorded in cultured intestinal ICCs at $-60 \mathrm{mV}$ of holding potential. Hypotonic stress activated sustained inward holding current and decreased amplitude of pacemaker current (Fig. 1Aa). The peak inward holding current was increased from the baseline to $-650 \pm 110 \mathrm{pA}$ (Fig. 1Ab, $\mathrm{n}=6, \mathrm{P}<0.05)$ and the amplitude of pacemaker current was decreased from $220 \pm 50 \mathrm{pA}$ to $140 \pm 50 \mathrm{pA}$ (Fig. $1 \mathrm{Ac}, \mathrm{n}=6$, $\mathrm{P}<0.05)$. However, hypotonic stress did not affect frequencies of pacemaker current and the frequencies were $11.38 \pm 1.31$ cycles $/ \mathrm{min}$ in control and $11.63 \pm 1.15$ cycles/min in hypotonic condition, respectively $(n=6$, $\mathrm{P}>0.05$ ). The above results have already published by Wang et al. (2010b).

It has been demonstrated that calcium and its oscillation are very important in generation of pacemaker currents (Lowie et al. 2011). So we observed the effect of hypotonic stress on calcium oscillation of ICCs. Cultured ICCs (48-72 h) preloaded with fluo-3, a high affinity $\mathrm{Ca}^{2+}$-sensitive indicator, exhibited spontaneous periodic calcium oscillation. When cells were exposed to hypotonic solution (220 mOsm), mean amplitude of spontaneous $\mathrm{Ca}^{2+}$ oscillation increased from $0.08 \pm 0.01$ to $0.19 \pm 0.03(\Delta \mathrm{F} / \mathrm{F} 0)$ and basal fluorescence intensity increased from baseline to $1.09 \pm 0.03(\mathrm{~F} / \mathrm{F} 0)$ (Fig. 1B, $\mathrm{n}=6, \quad \mathrm{P}<0.05)$. However hypotonic stress did not significantly change the frequencies of $\mathrm{Ca}^{2+}$ transients $(5.50 \pm 0.55$ cycles/min in control and $6.30 \pm 0.91$ cycles/min in hypotonic condition, respectively, $\mathrm{n}=6$, $\mathrm{P}>0.05)$.

Effect of cytochalasin-B on hypotonic stress-induced increase of pacemaker current and $\left[\mathrm{Ca}^{2+}\right]_{i}$

Actin microfilaments were necessary in regulation of cell response to physical forces (Higashida et al. 2013). Our previous study also demonstrated actin microfilament involves in regulation of pacemaker currents in cultured intestinal ICCs (Wang et al. 2010a). Cytochalasin B or D and phalloidin are the most common chemical compound to depolymerize and stabilize actin microfilaments (Faussone-Pellegrini and Thuneberg 1999, Gravante et al. 2004, Mazzochi et al. 2006). So in this study we used cytochalasin-B and phalloidin as disruptor and stabilizer of actin microfilaments. 


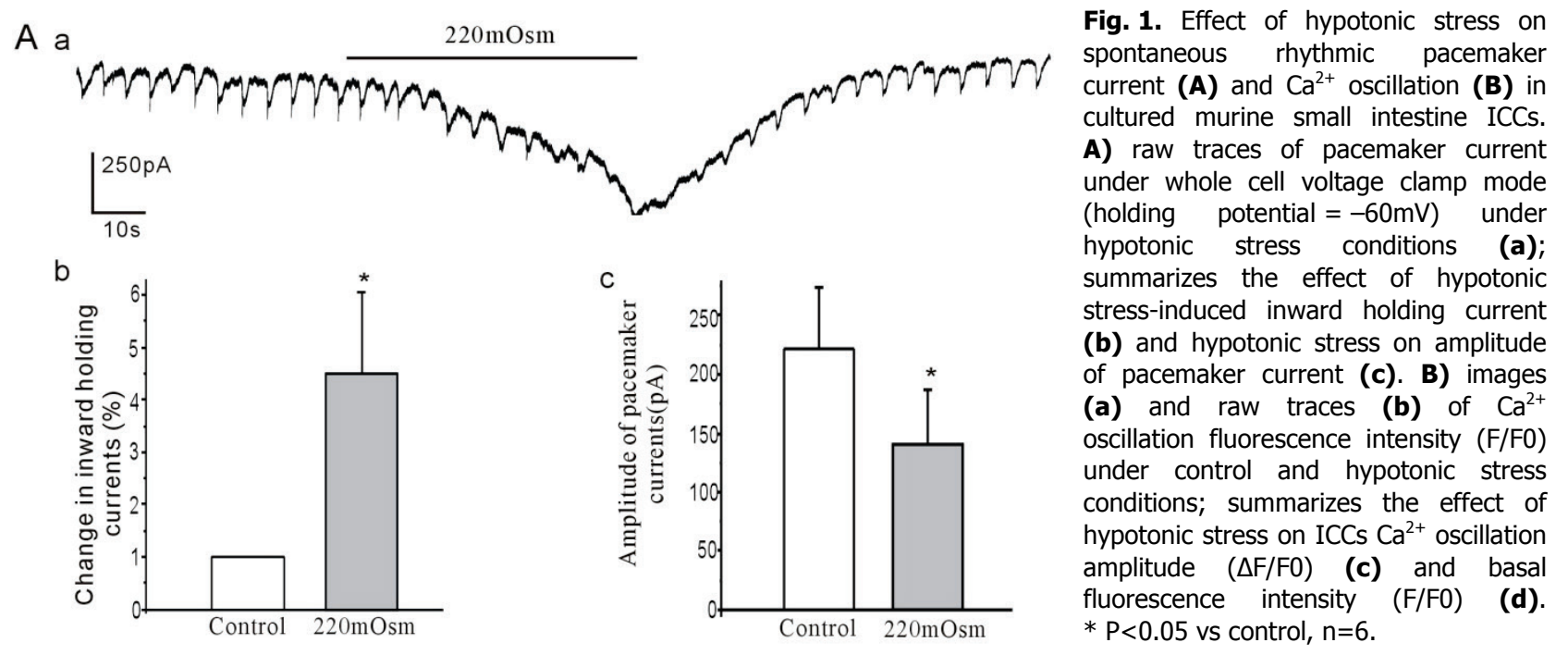

B a

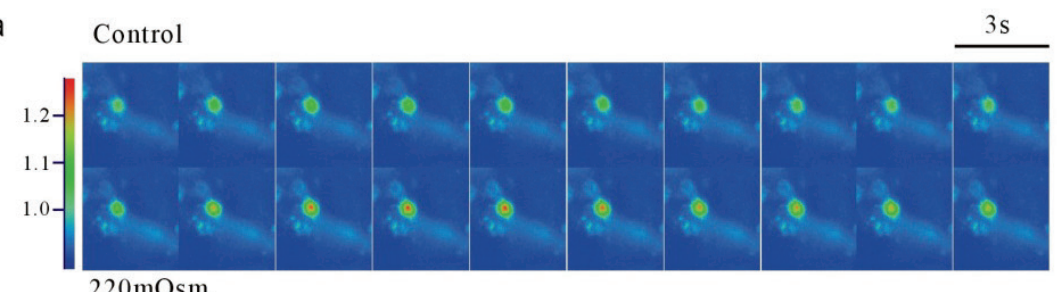

$220 \mathrm{mOsm}$

b

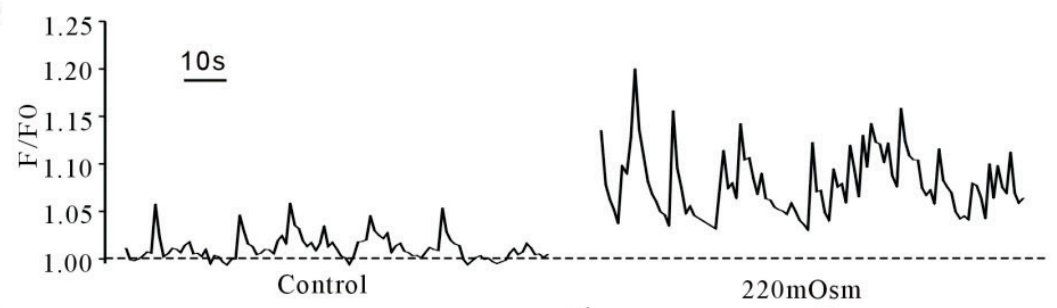

C

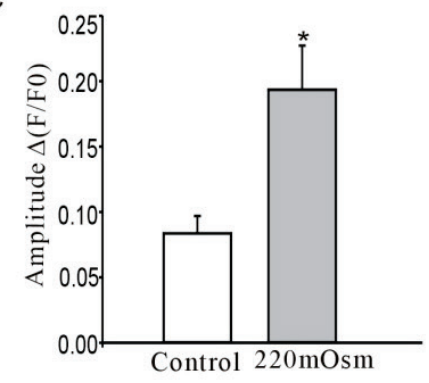

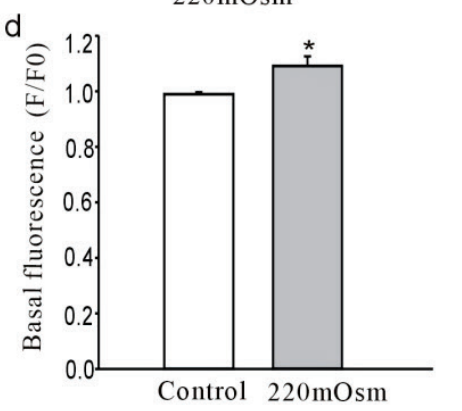

Under whole cell voltage clamp mode the spontaneous rhythmic inward pacemaker currents were recorded at $-60 \mathrm{mV}$ of holding potential. Addition of $20 \mu \mathrm{M}$ cytochalasin-B to the external perfusion solution significantly suppressed pacemaker currents (Fig. 2Aa). The amplitude and frequency of pacemaker currents were reduced from $490 \pm 160 \mathrm{pA}$ and $11.73 \pm 0.79 \mathrm{cycles} / \mathrm{min}$ to $230 \pm 90 \mathrm{pA}$ and $10.29 \pm 0.76$ cycles/min following cytochalasin-B treatment, respectively (Fig. 2B, $n=6$, $\mathrm{P}<0.05)$. Pretreatment of $20 \mu \mathrm{M}$ cytochalasin- $\mathrm{B}$ completely blocked the inward holding current induced by hypotonic stress (Fig. $2 \mathrm{Ab}, \mathrm{n}=6$ ). The amplitude of pacemaker currents was reduced from $230 \pm 90 \mathrm{pA}$ to $110 \pm 40 \mathrm{pA}$ following cytochalasin-B plus hypotonic stress treatment (Fig. $2 \mathrm{Ca}, \mathrm{n}=6, \mathrm{P}<0.05$ ). The frequency of pacemaker currents was changed from $10.29 \pm 0.76$ cycles $/ \mathrm{min}$ to $9.65 \pm 0.85$ cycles $/ \mathrm{min}$ following cytochalasin-B plus hypotonic stress treatment, (Fig. 2Cb, $\mathrm{n}=6, \mathrm{P}>0.05$ ). 


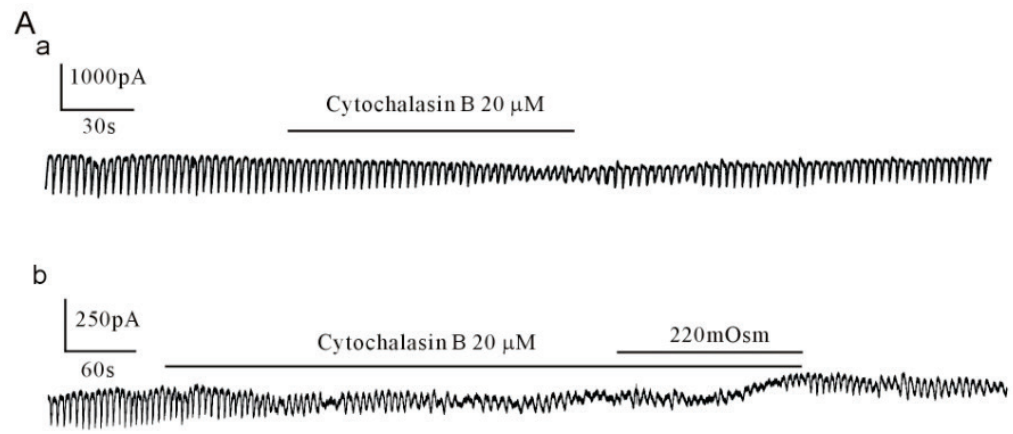

B

a

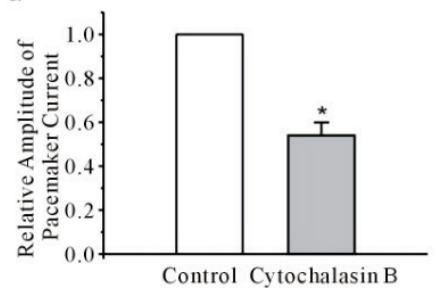

C

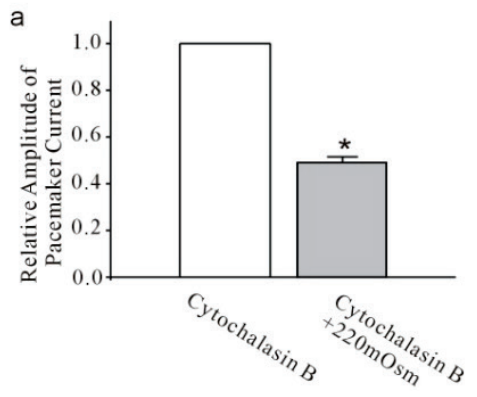

A

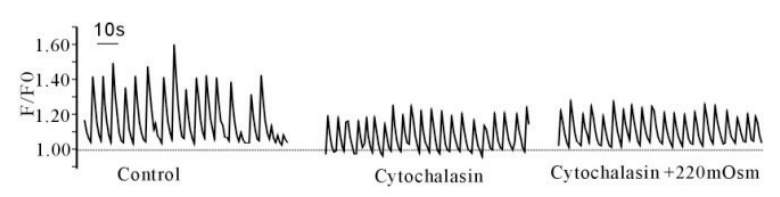

B
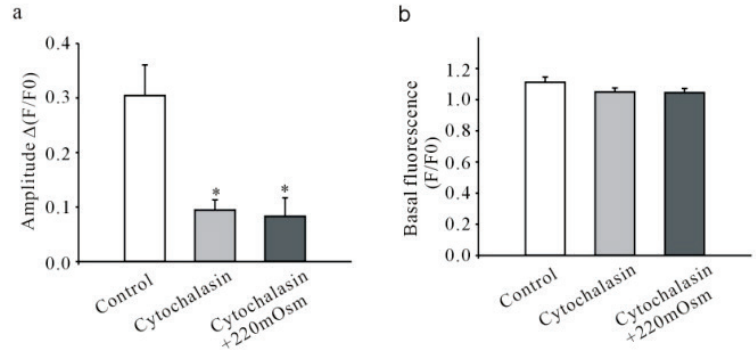

Fig. 3. Role of cytochalasin-B in regulating $\mathrm{Ca}^{2+}$ oscillation and hypotonic stress-induced increase effect in cultured murine small intestine ICCs. A) raw traces of $\mathrm{Ca}^{2+}$ oscillation fluorescence intensity (F/FO) of ICCs under control, cytochalasin and cytochalasin plus hypotonic stress conditions respectively; B) summarizes the effect of cytochalasin-B on $\mathrm{Ca}^{2+}$ oscillation amplitude $(\triangle \mathrm{F} / \mathrm{F} 0)$ (a) and basal fluorescence intensity (F/FO) (b) under normal and hypotonic stress condition. $* \mathrm{P}<0.05$ vs control, $n=6$.

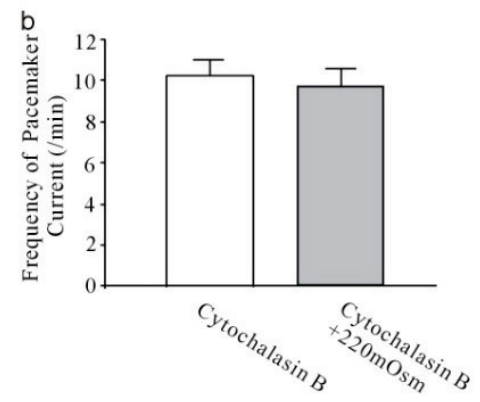

Fig. 2. Role of cytochalasin- $B$ in regulating pacemaker current and hypotonic stressinduced increase effect in cultured murine small intestine ICCs. A) raw traces of cytochalasin B-induced inhibition effect on pacemaker currents (a) and hypotonic stressinduced inward holding current (b). B) summarizes the effect of cytochalasin-B on pacemaker currents amplitude (a) and frequency (b). * $\mathrm{P}<0.05$ vs control, $\mathrm{n}=6$. C) summarizes the effect of cytochalasin-B plus hypotonic stress conditions on pacemaker currents amplitude (a) and frequency (b). * $\mathrm{P}<0.05$ vs cytochalasin- $\mathrm{B}, \mathrm{n}=6$.

Cytoskeleton regulates $\mathrm{Ca}^{2+}$ influx and release from intracellular calcium stores (Bose and Thomas 2009). To investigate the mechanisms of hypotonic stress on pacemaker currents, we tested the effect of cytochalasin-B on hypotonic stress-induced increase of periodic $\left[\mathrm{Ca}^{2+}\right]_{\mathrm{i}}$ oscillation. $20 \mu \mathrm{M}$ cytochalasin-B significantly suppressed calcium oscillations amplitude $(\Delta \mathrm{F} / \mathrm{F} 0)$ from $0.30 \pm 0.06$ to $0.09 \pm 0.02$ (Fig. $3 \mathrm{~A}, \mathrm{n}=6$, $\mathrm{P}<0.05)$. Pretreatment of cytochalasin-B completely blocked hypotonic stress-induced increase of the basal fluorescence intensity and the amplitude of calcium oscillations. The basal fluorescence intensity and amplitude $(\Delta \mathrm{F} / \mathrm{F} 0)$ of calcium oscillations were $1.05 \pm 0.03$ and $0.09 \pm 0.02$ in cytochalasin-B group and $1.04 \pm 0.03$ and $0.08 \pm 0.03$ in cytochalasin-B plus hypotonic stress group (Fig. 3B, $\mathrm{n}=6, \mathrm{P}>0.05$ ).

Effect of phalloidin on hypotonic stress-induced increase of pacemaker current and $\left[\mathrm{Ca}^{2+}\right]_{i}$

The spontaneous rhythmic inward pacemaker currents were recorded in same as the previous condition. 
$20 \mu \mathrm{M}$ phalloidin significantly enhanced pacemaker currents (Fig. 4Aa). The amplitude and frequency of pacemaker currents were increased from $750 \pm 280 \mathrm{pA}$ and $13.93 \pm 1.00$ cycles/min to $1230 \pm 610 \mathrm{pA}$ and $14.68 \pm 1.00$ cycles/min following phalloidin treatment, respectively (Fig. 4B, $\mathrm{n}=6, \mathrm{P}<0.05$ ). Moreover, pretreatment of phalloidin did not blocked hypotonic stress-induced inward holding current (Fig. 4Ab, $n=6$ ). The amplitude of pacemaker currents was reduced from $1230 \pm 610 \mathrm{pA}$ to $200 \pm 60 \mathrm{pA}$ following phalloidin plus hypotonic stress treatment (Fig. $4 \mathrm{Ca}, \mathrm{n}=6, \mathrm{P}<0.05$ ). The frequency of pacemaker currents was changed from $14.68 \pm 1.00$ cycles/min to $14.00 \pm 1.00$ cycles/min following phalloidin plus hypotonic stress treatment (Fig. $4 \mathrm{Cb}, \mathrm{n}=6, \mathrm{P}>0.05$ ).
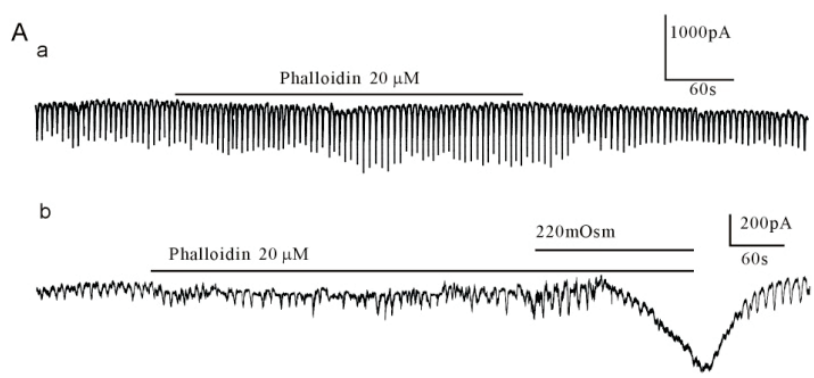

B
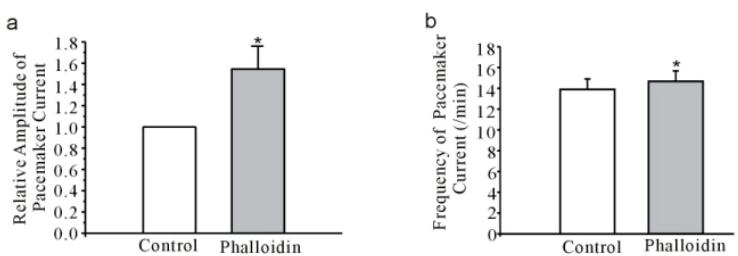

C
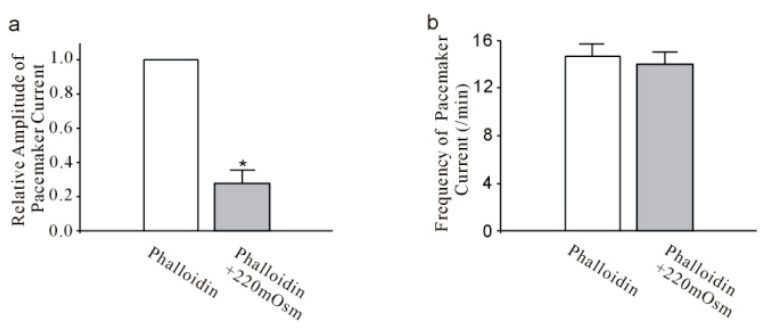

Fig. 4. Role of phalloidin in regulating pacemaker current and hypotonic stress-induced increase effect in cultured murine small intestine ICCs. A) raw traces of phalloidin-induced potentiation effect on pacemaker currents (a) and hypotonic stress-induced inward holding current (b). B) summarizes the effect of phalloidin on pacemaker currents amplitude (a) and frequency (b). $* \mathrm{P}<0.05$ vs control, $\mathrm{n}=6$. C) summarizes the effect of phalloidin plus hypotonic stress conditions on pacemaker currents amplitude (a) and frequency (b). $* \mathrm{P}<0.05$ vs phalloidin, $\mathrm{n}=6$.

$20 \mu \mathrm{M}$ phalloidin significantly potentiated calcium oscillations amplitude $(\Delta \mathrm{F} / \mathrm{F} 0)$ from $0.56 \pm 0.13$ to $0.72 \pm 0.08$ (Fig. 5A, Ba, $\mathrm{n}=6, \mathrm{P}<0.05$ ). Hypotonic stress- induced increase in the amplitude $(\Delta \mathrm{F} / \mathrm{F} 0)$ of calcium oscillations was blocked by pretreatment with phalloidin. The calcium oscillations amplitude $(\Delta \mathrm{F} / \mathrm{F} 0)$ were $0.72 \pm 0.08$ in phalloidin group and $0.68 \pm 0.12$ in phalloidin plus hypotonic stress group (Fig. $5 \mathrm{~A}, \mathrm{Ba}, \mathrm{n}=6$, $\mathrm{P}>0.05$ vs hypotonic stress plus phalloidin group). However, pretreatment of phalloidin did not blocked hypotonic stress-induced increase in basal fluorescence intensity and the basal $\Delta \mathrm{F} / \mathrm{F} 0$ was enhanced from baseline to $1.32 \pm 0.07$ by hypotonic stress after pretreatment of phalloidin (Fig. $5 \mathrm{~A}, \mathrm{Bb}, \mathrm{n}=6, \mathrm{P}<0.05$ ).

A

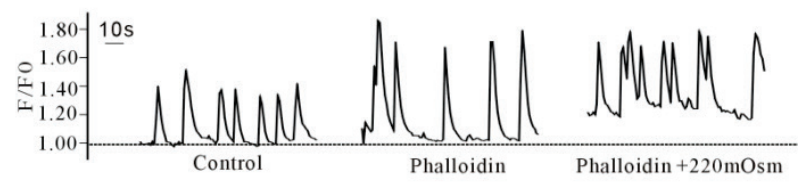

B

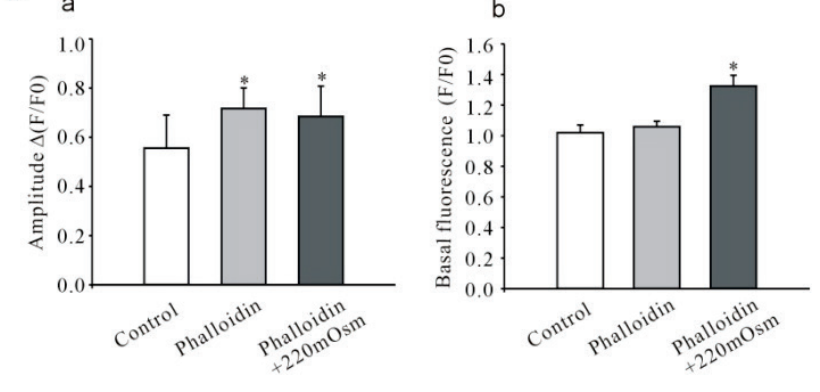

Fig. 5. Role of phalloidin in regulating $\mathrm{Ca}^{2+}$ oscillation and hypotonic stress-induced increase effect in cultured murine small intestine ICCs. A) raw traces of $\mathrm{Ca}^{2+}$ oscillation fluorescence intensity (F/FO) of ICCs under control, phalloidin and phalloidin plus hypotonic stress conditions respectively; B) summarizes the effect of phalloidin on $\mathrm{Ca}^{2+}$ oscillation amplitude $(\Delta \mathrm{F} / \mathrm{F} 0)(\mathrm{a})$ and basal fluorescence intensity (F/FO) (b) under normal and hypotonic stress condition. $* \mathrm{P}<0.05$ vs control, $\mathrm{n}=6$.

\section{Discussion}

Distension is one of the major stimuli to induce motor activity in GI smooth muscle. It is speculated that parts of the cellular apparatus including ionic conductance(s) regulate membrane potential and excitability during distension of the bowel wall and this may be an important aspect of the 'myogenic response' to stretch (Won et al. 2013). Also the myogenic mechanism for the stretch-induced increase in contractility of smooth muscle in GI tract is not clear and it has been reported that intact cytoskeleton is related to mechanosensitivity (Kraichely and Farrugia 2007). Our previous study indicated that actin microfilament is involved in 
generation of pacemaker current in cultured intestinal ICCs and the mechanism is related to IP3-induced calcium release (IICR) (Wang et al. 2010a). The present study demonstrates that hypotonic stress activated sustained inward holding current and actin microfilaments were implicated in the process. Our results suggest that hypotonic stress may be important stimuli to regulate the pacemaking activity in intestinal ICCs via actin microfilaments.

Several mechanosensitive channels have been reported to be related to the myogenic mechanism, such as L-type $\mathrm{Ca}^{2+}$ channel (Kraichely et al. 2009), stretchdependent $\mathrm{K}^{+}$(SDK) channels (Won et al. 2013) and stretch-activated non-selective cation channels (Wang et al. 2003). ICCs generate spontaneous electrical slow wave activity, conduct a rhythmic impulse to smooth muscle cells and mediate the propagation of the slow waves (Ward and Sanders 2001). This may indicate that ICCs may play a functional role in regulation of stretchinduced rhythmic motor activity. $\mathrm{Ca}^{2+}$-dependent plasma membrane ion channels are responsible for mediating ICCs pacemaker potential (Lowie et al. 2011). In this study, we have found that hypotonic stress elicited a large inward holding current and reduced the amplitude of the pacemaker current generated by ICCs (Fig. 1A). These findings suggest that distension or stretch stimulus may regulate motor activity of GI tract via changing pacemaking activity of ICCs. This is coincidence with the report that many kinds of mechanosensitivity channels are existed in ICCs of GI tract and participate in regulating cell response to force with a change in their open probability (Kraichely and Farrugia 2007). These results may support the previous observation showing a mechanosensitive role for interstitial cells of Cajal in smooth muscle tissues (Won et al. 2005).

The actomyosin cytoskeleton is a large network of structural, motor and signaling proteins that coordinate a plethora of cellular functions including cell division, adhesion and migration. Actin microfilaments were necessary in regulation of cell response to physical forces (Higashida et al. 2013). The activities of various transport proteins as well as ion and water permeable channels have been shown to be dependent on the extent of actin polymerization (Prat et al. 1993, Constantin 2013). Some mechanosensitive channels have been reported to be related to cytoskeleton, like stretch-dependent potassium channels (Koh and Sanders 2001) and muscarinic current (Wang et al. 2003) in GI smooth muscle and Nav1.5 and voltage-gated $\mathrm{Ca}^{2+}$ channel (Kraichely and Farrugia 2007) in ICCs of GI tract. In this study, depolymerized actin microfilament inhibited pacemaker current of ICCs and blocked hypotonic stress-induced inward holding current (Fig. 2). In contrast, more polymerized actin microfilament increased pacemaker current of ICCs and did not block the inward holding current induced by hypotonic stress (Fig. 4). These results indicate that actin microfilaments participate in the generation of pacemaking activity of ICCs and also play a key role in the action of hypotonic stress to intensify electrical activities of ICCs.

The oscillations of intracellular calcium $\left(\left[\mathrm{Ca}^{2+}\right]_{\mathrm{i}}\right)$ observed in ICCs can periodically activate plasma membrane low $\mathrm{Ca}^{2+}$-dependent ion channels, thereby generating pacemaker potentials (Nose et al. 2000, van Helden et al. 2000). Our previous studies have indicated that hypotonic stress potentiates muscarinic currents and depolarizes membrane potential by triggering ryanodine sensitive $\left[\mathrm{Ca}^{2+}\right]_{i}$ store in gastric myocytes of guinea-pig (Li et al. 2002, Yu et al. 2002). To investigate the mechanism by which hypotonic stress increases the pacemaking activity, we further examined the effect of hypotonic stress on calcium oscillations by using the calcium imaging technique. Our data showed that hypotonic stress significantly enhances intracellular basal calcium concentrations and potentiates spontaneous $\mathrm{Ca}^{2+}$ oscillation amplitudes (Fig. 1B). This result suggests that the increase in $\left[\mathrm{Ca}^{2+}\right]_{i}$ induced by hypotonic stress maybe one of the key mechanism underlying the effect of hypotonic stress on pacemaker current. Our previous study also observed that 2-APB, an $\mathrm{IP}_{3}$ receptor blocker, blocked both pacemaker current and $\mathrm{Ca}^{2+}$ transients but did not alter the effect of hypotonic stress on pacemaker current and $\mathrm{Ca}^{2+}$ transients. In contrast, ryanodine inhibited $\mathrm{Ca}^{2+}$ transients but not pacemaker current, and completely blocked hypotonic stress-induced inward holding current and hypotonic stress-induced increase of basal $\left[\mathrm{Ca}^{2+}\right]_{\mathrm{i}}$ (Wang et al. 2010b). Thus, we presume that hypotonic stress-induced holding inward current may be mediated by enhancement of $\left[\mathrm{Ca}^{2+}\right]_{\mathrm{i}}$ from ryanodine-sensitive store.

The cytoskeleton plays an important role in regulating $\mathrm{Ca}^{2+}$ influx or releasing (Bose and Thomas 2009). Young et al. (1997) found that cultured myocytes from the circular muscle layer of the rabbit distal colon responded to brief focal mechanical deformation of the plasma membrane with a transient increase in intracellular calcium concentration. They suggested that a communication between the plasma membrane and an internal $\mathrm{Ca}^{2+}$ store may be mediated by direct mechanical link via actin filaments. This is also supported by our results that 
depolymerized actin microfilament inhibited calcium oscillation amplitudes of ICCs and blocked hypotonic stressinduced increase of basal calcium concentrations (Fig. 3). In contrast, the stabilizer of actin microfilament increased calcium oscillations amplitude of ICCs and did not inhibit the increase of basal calcium concentration (Fig. 5). The results suggest that actin microfilament regulates the effect of hypotonic stress on pacemaker current via changing intracellular calcium concentration.

\section{Conclusion}

Hypotonic stress can regulate gastrointestinal smooth motility by potentiating ICCs pacemaking activity. Actin microfilaments are involved in the regulation of pacemaker currents by hypotonic stress via alteration of $\left[\mathrm{Ca}^{2+}\right]_{\mathrm{i}}$. Polymerized types of actin is vital for ICCs pacemaker activity response to stretch stimulation.

\section{Conflict of Interest}

There is no conflict of interest.

\section{Acknowledgements}

This study was funded by Grant No.10672103; 31271236 provided by National Natural Science Foundation of China.

\section{References}

ARANISHI H, KUNISAWA Y, KOMURO T: Characterization of interstitial cells of Cajal in the subserosal layer of the guinea-pig colon. Cell Tissue Res 335: 323-329, 2009.

BOSE DD, THOMAS DW: The actin cytoskeleton differentially regulates NG115-401L cell ryanodine receptor and inositol 1,4,5-trisphosphate receptor induced calcium signaling pathways. Biochem Biophys Res Commun 379: 594-599, 2009.

BURNS AJ, LOMAX AE, TORIHASHI S, SANDERS KM, WARD SM: Interstitial cells of Cajal mediate inhibitory neurotransmission in the stomach. Proc Natl Acad Sci USA 93: 12008-12013, 1996.

CONSTANTIN B: Dystrophin complex functions as a scaffold for signalling proteins. Biochim Biophys Acta 1838: 635-642, 2014.

COREY DP, GARCÍA-AÑOVEROS J, HOLT JR, KWAN KY, LIN SY, VOLLRATH MA, AMALFITANO A, CHEUNG EL, DERFLER BH, DUGGAN A, GÉLÉOC GS, GRAY PA, HOFFMAN MP, REHM HL, TAMASAUSKAS D, ZHANG DS: TRPA1 is a candidate for the mechanosensitive transduction channel of vertebrate hair cells. Nature 432: 723-730, 2004.

FAUSSONE-PELLEGRINI MS, THUNEBERG L: Guide to the identification of interstitial cells of Cajal. Microsc Res Tech 47: 248-266, 1999.

GRAVANTE B, BARBUTI A, MILANESI R, ZAPPI I, VISCOMI C, DIFRANCESCO D: Interaction of the pacemaker channel HCN1 with filamin A. J Biol Chem 279: 43847-43853, 2004.

HIGASHIDA C, KIUCHI T, AKIBA Y, MIZUNO H, MARUOKA M, NARUMIYA S, MIZUNO K, WATANABE N: F- and G-actin homeostasis regulates mechanosensitive actin nucleation by formins. Nat Cell Biol 15: 395-405, 2013.

KIM BJ, SO I, KIM KW: The relationship of TRP channels to the pacemaker activity of interstitial cells of Cajal in the gastrointestinal tract. J Smooth Muscle Res 42: 1-7, 2006.

KOH SD, SANDERS KM: Stretch-dependent potassium channels in murine colonic smooth muscle cells. $J$ Physiol 533: 155-163, 2001.

KRAICHELY RE, FARRUGIA G: Mechanosensitive ion channels in interstitial cells of Cajal and smooth muscle of the gastrointestinal tract. Neurogastroenterol Motil 19: 245-252, 2007.

KRAICHELY RE, STREGE PR, SARR MG, KENDRICK ML, FARRUGIA G: Lysophosphatidyl choline modulates mechanosensitive L-type $\mathrm{Ca} 2+$ current in circular smooth muscle cells from human jejunum. Am J Physiol Gastrointest Liver Physiol 296: G833- G839, 2009.

LI L, JIN NG, PIAO L, HONG MY, JIN ZY, LI Y, XU WX: Hyposmotic membrane stretch potentiated muscarinic receptor agonist-induced depolarization of membrane potential in guinea-pig gastric myocytes. World $J$ Gastroenterol 8: 724-727, 2002. 
LOWIE BJ, WANG XY, WHITE EJ, HUIZINGA JD: On the origin of rhythmic calcium transients in the ICC-MP of the mouse small intestine. Am J Physiol Gastrointest Liver Physiol 301: G835-G845, 2011.

MAROTO R, RASO A, WOOD TG, KUROSKY A, MARTINAC B, HAMILL OP: TRPC1 forms the stretch-activated cation channel in vertebrate cells. Nat Cell Biol 7: 179-185, 2005.

MAZZOCHI C, BENOS DJ, SMITH PR: Interaction of epithelial ion channels with the actin-based cytoskeleton. $A m J$ Physiol Renal Physiol 291: F1113-F1122, 2006.

NOSE K, SUZUKI H, KANNAN H: Voltage dependency of the frequency of slow waves in antrum smooth muscle of the guinea-pig stomach. Jpn J Physiol 50: 625-633, 2000.

PRAT AG, BERTORELLO AM, AUSIELLO DA, CANTIELLO HF: Activation of epithelial Na+ channels by protein kinase A requires actin filaments. Am J Physiol 265: C224- C233, 1993.

SANDERS KM: Regulation of smooth muscle excitation and contraction. Neurogastroenterol Motil 20 (Suppl 1): 39-53, 2008.

SANDERS KM, KOH SD, WARD SM: Interstitial cells of Cajal as pacemakers in the gastrointestinal tract. Annu Rev Physiol 68: 307-343, 2006.

STREGE PR, OU Y, SHA L, RICH A, GIBBONS SJ, SZURSZEWSKI JH, SARR MG, FARRUGIA G: Sodium current in human intestinal interstitial cells of Cajal. Am J Physiol Gastrointest Liver Physiol 285: 1111-1121, 2003.

VAN HELDEN DF, IMTIAZ MS, NURGALIYEVA K, VON DER WEID P, DOSEN PJ: Role of calcium stores and membrane voltage in the generation of slow wave action potentials in guinea-pig gastric pylorus. $J$ Physiol 524: 245-265, 2000.

WANG ZY, YU YC, CUI YF, LI L, GUO HS, LI ZL, XU WX: Role of actin microfilament in hyposmotic membrane stretch-induced increase in muscarinic current of guinea-pig gastric myocytes. Sheng Li Xue Bao 55: 177-182, 2003.

WANG ZY, HAN YF, HUANG X, LU HL, GUO X, KIM YC, XU WX: Actin microfilament involved in regulation of pacemaking activity in cultured interstitial cells of Cajal from murine intestine. J Membr Biol 234: 217-225, 2010a.

WANG ZY, HAN YF, HUANG X, ZHAO P, LU HL, KIM YC, XU WX: Pacemaking activity is regulated by membrane stretch via the CICR pathway in cultured interstitial cells of Cajal from murine intestine. $J$ Biomech 43: 2214-2220, 2010 b.

WARD SM, SANDERS KM: Physiology and pathophysiology of the interstitial cells of Cajal: from the bench to bedside. I. Functional development and plasticity of interstitial cells of Cajal networks. Am J Physiol Gastrointest Liver Physiol 281: G602-G611, 2001.

WON KJ, SANDERS KM, WARD SM: Interstitial cells of Cajal mediate mechanosensitive responses in the stomach. Proc Natl Acad Sci USA 102: 14913-14918, 2005.

WON KJ, SANDERS KM, WARD SM: Stretch-dependent sensitization of post-junctional neural effectors in colonic muscles. Neurogastroenterol Motil 25: e101-e113, 2013.

YOUNG SH, ENNES HS, MAYER EA: Mechanotransduction in colonic smooth muscle cells. J Membr Biol 160: 141-150, 1997.

YU YC, GUO HS, PIAO L, LI L, LI ZL, XU WX: Intracellular calcium was involved in muscarinic currents increased by hypoosmotic membrane stretch in gastric myocytes of guinea pig. Acta Pharmacol Sin 23: 1007-1012, 2002.

ZHANG Y, PIAO LH, HUANG X, HAN YF, ZHAO P, GAO L, KIM Y, XU WX: Pacemaker currents modulated by C-type natriuretic peptide in interstitial cells of cajal from murine small intestine. $J$ Physiol Biochem 62: 281-291, 2006. 